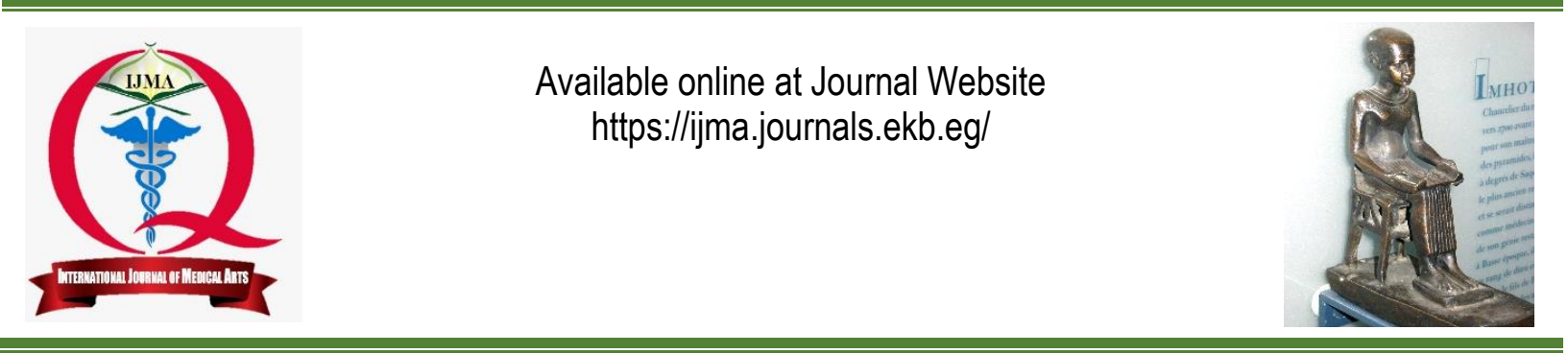

Original article

\title{
Hypertension and Health-Related Quality of Life: A Community Based Epidemiological Study in an Egyptian Village
}

Mohamed Ahmed Elmosalamia; Ayman Ahmed Mahammoud ${ }^{\text {b; }}$ Marzouk Al-Khawaja ${ }^{b}$

Department of Public Health and Community Medicine, Faculty of Medicine, Al-Azhar University, Egypt [a]

Department of Public Health and Community Medicine, Damietta Faculty of Medicine, Al-Azhar University, Egypt[b]

Corresponding author: Marzouk Al-Khawaja

Email: Marzouk.mmg@domazhermedicine.edu.eg

Received at: December 4, 2019; Revised at: December 27, 2020; Accepted at: January 26, 2020; Available online at: January 27, 2020

\section{ABSTRACT}

Background: High blood pressure is the most important modifiable risk factor for stroke, associated with $54 \%$ episodes of stroke worldwide and $45 \%$ of Ischemic Heart Disease deaths are attributable to high systolic blood pressure.

Aim of the work: To identify the prevalence rate of hypertension among adult inhabitants of Badaway village, Al-Mansoura District, Al-Dakahlia Governorate, to identify the epidemiological characteristics and risk factors of hypertension compared to non-hypertension individuals, to assess the (HRQOL) among hypertensive patients compared to non- hypertension individuals, and to evaluate the effect of an educational health program on health-related quality of life (HRQOL) among hypertensive patients.

Subjects and methods: The study was conducted on 1100 of adult populations aged 30 years and older living at the studied village, A cross sectional study using questionnaire to assess the participant's HRQOL by SF-36 questionnaire, and interventional study included application of intervention program on hypertension group.

Results: The total prevalence of hypertension was $28.2 \%$ of the total studied sample. The important predictor's factors were overweight, obese, older age, unmarried status, employment, and high socioeconomic level. The mean of Physical Component Summary and Mental Component Summary and their items of HRQOL were statistically higher among the normal group compared with hypertension group. The intervention program has a significant effect on improving means of PCS and MCS of HRQOL.

Conclusion: Application of simple health education intervention program can lead to significant positive impact on knowledge, behaviors and HRQOL of hypertension patients.

Keywords: Hypertension; Quality of Life; Health program; Educational intervention; Rural.

This is an open access article under the Creative Commons license [CC BY] [https://creativecommons.org/licenses/by/2.0/]

Please cite this article as: Elmenawy MM, Salama FH, El-Shoura SA, Hussein AFA Surgical Treatment of Unstable Pelvic Ring Fracture by Anterior Plating of Sacroiliac Joint. IJMA 2020; 2[1]: 232-240. 


\section{INTRODUCTION}

The global prevalence of hypertension in adults aged 18 years and over was around 22\%[1]. In Egypt (2016) MOHP published that $17 \%$ of women and men were classified as hypertensive[2]. The problem is complicated by the low awareness rates, only $38 \%$ of hypertensive Egyptians were aware of having high blood pressure, only $24 \%$ were receiving treatment, whereas control rates (<140/90 $\mathrm{mmHg}$ ) were $8 \%[3]$.

Health-related quality of life (HRQOL) has become increasingly important in clinical and public health research over the last 15 years [4]. Health- related quality of life (HRQOL) provides a multi-dimensional perspective encompassing a patient's emotional, physical, and social functioning ${ }^{[5]}$ HRQOL Measuring can help to determine the burden of preventable disease, injuries, and disabilities, and it can provide valuable new insights into the relationships between HRQOL and risk factors[6]. There are many general instruments available to measure the quality of life, but the 36-item short-form (SF-36) health survey is the most popular generic HRQOL instrument that has been widely used to measure several population studies and a variety of health conditions, including hypertension ${ }^{[7]}$.

The SF-36 measures eight scales: physical functioning (PF), role physical (RP), bodily pain (BP), general health (GH), vitality (VT), social functioning (SF), role emotional (RE), and mental health $(\mathrm{MH})$. The 8 subscales contribute to two, resulting in component summaries: a mental component summary (MCS) and a physical component summary (PCS). Both PCS and MCS scores range from 0 to 100 , representing the worst to better health. Higher scores indicate better HRQOL [8].

Previous investigations have shown that clinical and sociodemographic variables affect the patient's quality of life, reporting that in hypertension patients there is a decrease in it[9]. However, some studies have concluded the opposite and state that there is no decrease in the quality of life of hypertension patients[10].

Several studies have demonstrated that hypertension has a strong negative impact on HRQOL[11]. There is a lack of information on the role of a health education intervention on the quality of life in patients with hypertension. Therefore, it can be hypothesized that imparting health education to patients through a well-designed intervention can result in better awareness, behaviors toward the disease and improved HRQOL[12]. Community physicians can play an important role to help hypertension patients to gain knowledge and change attitudes necessary to live with controlled hypertension and good HRQOL[13]. From this point of view, this community based epidemiological research work was conducted to investigate the current topic.

\section{AIM OF THE WORK}

To identify the prevalence rate of hypertension among adults in Badaway village, Al- Mansoura District, Al-Dakahlia Governorate. In addition, to evaluate the effect of an educational health program on HRQOL among hypertensive patients

\section{PATIENTS AND METHODS}

This research deals with hypertension and HRQOL and was performed from the beginning of June 2017 to November 2019 at Badaway Village, AlMansoura District, Al- Dakahlia Governorate.

Sampling design: The study involved two sampling methods:

A. Sample for the preliminary assessment, the studied village was divided into eight separate clusters and then randomly selected four clusters using simple random sampling technique. Based on the inclusion and exclusion criteria, the selected sample size was taken from the selected four clusters by house to house method to Identify the prevalence rate of hypertension and comparison of sociodemographic variables, risk factors and $\mathrm{HRQOL}$ domains between hypertension and normotension groups.

Inclusion criteria: Participants with age 30 years and older. Exclusion criteria: severe psychiatric or behavioral disorders, pregnant females, participants who are less than 30 years old and participants with current chronic disease affecting HRQOL.

The sample size was calculated using StatCalc software, Epi-info version 7 based on the following assumption: The total number of populations in the studied village was 58695, The number of populations with age 30 years and over was 28550 . Prevalence of hypertension by $50 \%$ (to give maximum sample size) and Confidence level $97 \%$. This was given a minimum sample size of 1066; to compensate for any incomplete questionnaire and 
sampling error, this number was rounded to 1100 .

$B$. Sample for an intervention program: A subsample of 200 hypertensive patients was drawn from the study patients by simple random sampling, then the sub-sample was randomly divided into two equal groups. The researcher taught the health education program only to the experimental group (100 patients) while the control group (100 patients) did not. The experimental group was divided into 10 small groups; each group (10 hypertensive patients) attended 4 sessions and the total number of sessions was around 40 sessions over 2 months for the whole experimental group.

\section{The Interventional patient's Program:}

A group-based educational intervention session on hypertension was conducted by a researcher at the village's family health center and included the teaching program schedule and PowerPoint, posters and copyright disk (CD) videos to meet the overall goals of the program. The hypertensive patients in the intervention group were contacted by telephone to attend the intervention program. The length of each session ranged from 40-60 minutes, starting with 5 minutes warming up to 20 minutes of lecture, followed by group discussion for questions and answers for 15-30 minutes. The content of the program and the choice of methods of teaching were based on the age, educational level and needs of the patient, individually or in groups. The researcher prepared an informative PowerPoint poster, and videos on copyright disk, CD using simple language and illustrative images to present information to patients in a simple way.

This study was divided into two phases:

1. Cross-sectional study: was carried out to determine the following items by completing questionnaire sheets; socio-demographic variables, hypertension-related data, hypertension prevalence and also to measurement of HRQOL by the short form 36 Questionnaire.

2. Interventional study (A health education program): the researcher educated and informed the experimental group on the health education program while the control group was not. after six months, evaluation of the program was done using the same pretest questionnaire.

Statistical analysis of the data: Data was analyzed by using statistical package for social science [SPSS] software, version 25 [IBM®SPSS $®$, USA, Chicago, IL]. Quantitative data were tested for normality by using the Kolmogorov-Smirnov test and expressed as means with standard deviation or medians with ranges according to data distribution. Categorical data were presented as number and percentages. $P$ $<0.05$ is considered significant. Groups were compared by Chi-Square test and Student [t] test. Binary logistic regression analysis was conducted to identify independent significant hypertension predictors, and independent variables had $p$-value $\leq$ 0.05 candidates for multiple logistic regression analyses with Odds ratios (OR) at 95\% confidence intervals $(\mathrm{Cl})$ was calculated and statistical significance were accepted at the 5\% (P-value $\leq$ 0.05).

\section{RESULTS}

The current study showed that hypertension was present in more than one fourth $(28.2 \%)$ of the study participants. The prevalence of hypertension among females was slightly higher than males, $(29.2 \%)$ compared to $(26.8 \%)$ respectively [Table 1]. The current study revealed that after the addition of significant predictors in the logistic regression model: age groups (60-69 and > 70 years), marital status, basic education, jobs, socio-economic levels (middle and high levels) and BMI (overweight and obese groups) continued a significantly associated predictor $(P=0.001)$. In addition, the age group (40-49 and 5059 years) and educational levels (high and university) were still not significantly associated to predictors. [Table (2)]. The current study also revealed that, after using the model of multiple logistic regression: overweight, obese groups, and high socio-economic levels, there are significant risks of developing hypertension compared to their reference groups $(P=0.001)$. Compared to their reference groups, marriage and employment also have a significantly higher risk of having hypertension $(P=0.001)$. Overweight, high socio-economic status, older age, working, unmarried and obese were $(9.4,5.3,3.2$, $3.2, \quad 2.5$ and 2.3 times respectively) significantly more risky to develop hypertension compared to their reference group $(P=0.001 \& P=0.001)$ [Table 2]. The physical (PCS) and mental (MCS) component summary and their items of HRQOL were statistically higher in the normal group compared with the hypertension group $(P=0.001)$ [Table 3]. As a result of the intervention program, the physical (PCS) and mental (MCS) component summary and their items of 
HRQOL were enhanced and significantly higher in the $\quad(P=0.001)$ [Table 4 and Figure 1] experimental group compared to the control group

Table [1]: Prevalence of hypertension in the study sample according to sex

\begin{tabular}{|cccc|}
\hline \hline Sex & Total studied sample (No.) & Hypertension (No.) & Prevalence (\%) \\
\hline Male & 481 & 129 & 26.8 \\
Female & 619 & 181 & 29.2 \\
Total & 1100 & 310 & 28.2 \\
\hline
\end{tabular}

Table [2]: Multiple logistic regressions of risk factors associated with hypertension as predictors of the occurrence of hypertension among affected group

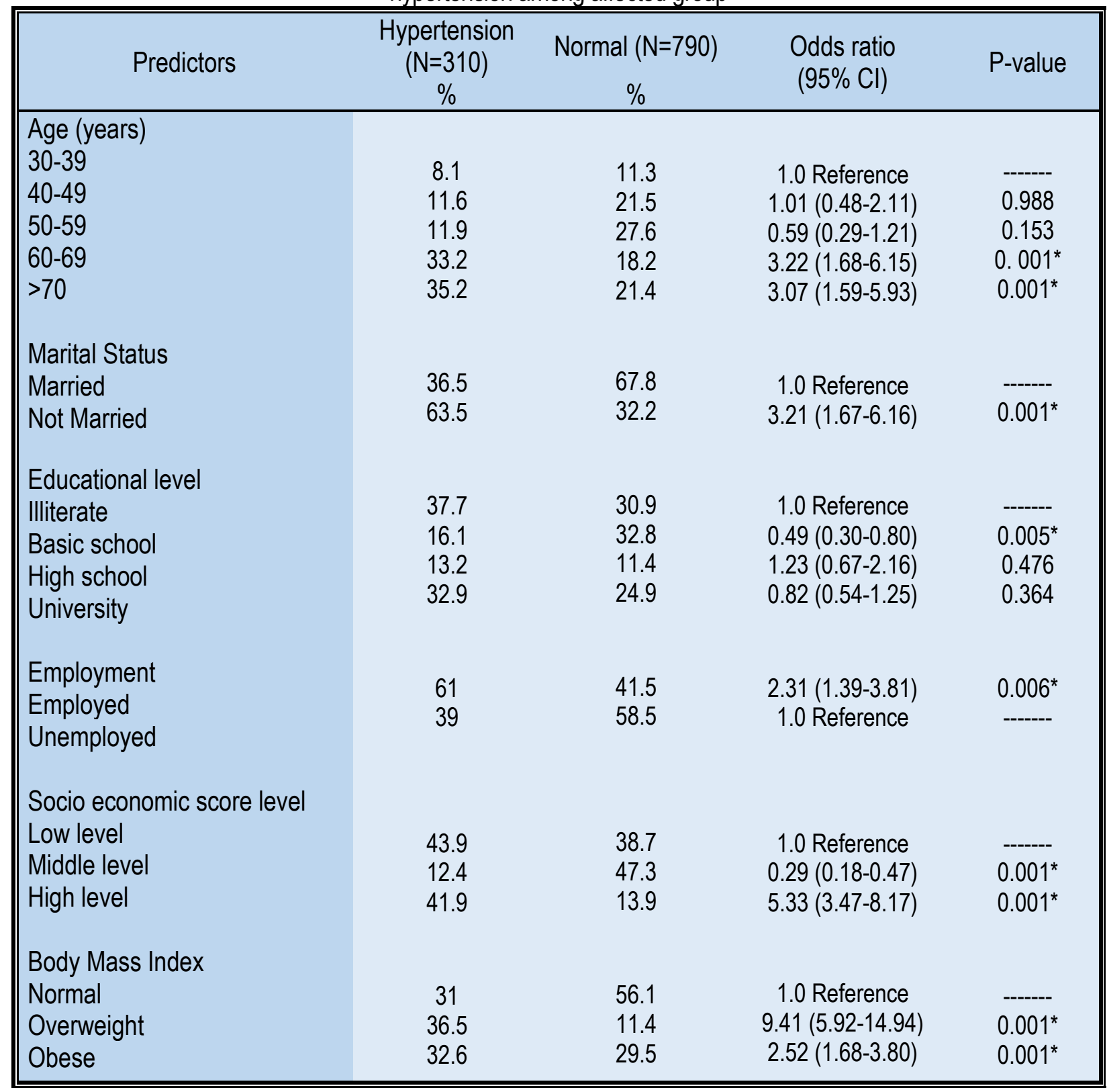

* significant difference. 
Elmosalami MA, et al.

\begin{tabular}{|c|c|c|c|c|}
\hline HRQOL Domains & $\begin{array}{c}\text { Hypertension ( } \mathrm{N}=310 \text { ) } \\
\text { Mean (SD) }\end{array}$ & $\begin{array}{c}\text { Normal }(\mathrm{N}=790) \\
\text { Mean (SD) }\end{array}$ & T & $P$ value \\
\hline General Health & $40.8(10.3)$ & $79.2(11.9)$ & 49.9 & $0.001^{*}$ \\
\hline Bodily Pain & $41.3(9.7)$ & $79.6(12.7)$ & 47.9 & $0.001^{*}$ \\
\hline Physical Functioning & $45.1(16.2)$ & $78.6(12.3)$ & 37.0 & $0.001^{*}$ \\
\hline Role Limitation Physical & $40.7(9.6)$ & $81(10.5)$ & 58.4 & $0.001^{*}$ \\
\hline PCS & $42.7(13.2)$ & $79.9(9.7)$ & 51.6 & $0.001^{*}$ \\
\hline Social Functioning & $42.5(12.4)$ & $78.3(13.9)$ & 39.4 & $0.001^{*}$ \\
\hline Role Limitation Emotional & $45.7(8.6)$ & $77.9(12.2)$ & 42.6 & $0.001^{*}$ \\
\hline Vitality & $37.9(9.8)$ & $75.1(13.9)$ & 42.9 & $0.001^{*}$ \\
\hline Mental Health & $44.8(14.5)$ & $77.5(12.6)$ & 36.9 & $0.001^{*}$ \\
\hline MCS & $39.7(13.1)$ & $80.2(10.7)$ & 52.9 & $0.001^{*}$ \\
\hline
\end{tabular}

Table [4]: Comparison between the experimental and control groups regarding their generic health-related quality of life after the intervention program

\begin{tabular}{|c|c|c|c|c|}
\hline \multirow{2}{*}{ HRQOL Domains } & Experimental & Control & \multirow[t]{2}{*}{$\mathrm{T}$} & \multirow[t]{2}{*}{$P$ value } \\
\hline & Mean (SD) & Mean (SD) & & \\
\hline General Health & $79.5(11.5)$ & $40.9(10.1)$ & 25.3 & $0.001^{*}$ \\
\hline Bodily Pain & $79.8(12.1)$ & $40.5(8.4)$ & 26.5 & $0.001^{*}$ \\
\hline Physical Functioning & $78.3(12.5)$ & $45.9(14.7)$ & 16.8 & $0.001^{*}$ \\
\hline Role Limitation Physical & $81.2(10.4)$ & $39.8(9.1)$ & 29.9 & $0.001^{*}$ \\
\hline PCS & $80.5(9.5)$ & $42.4(13.3)$ & 23.3 & $0.001^{*}$ \\
\hline Social functioning & $79.4(13.2)$ & $42.5(11.9)$ & 20.8 & $0.001^{*}$ \\
\hline Role Limitation Emotional & $77.3(12.5)$ & $46.1(8.4)$ & 20.6 & $0.001^{*}$ \\
\hline Vitality & $75(13.5)$ & $37.7(9.9)$ & 22.3 & $0.001^{*}$ \\
\hline Mental health & $77.1(12.8)$ & $44.6(13.6)$ & 17.4 & $0.001^{*}$ \\
\hline MCS & $79.9(10.3)$ & $39.9(12.8)$ & 24.3 & $0.001^{*}$ \\
\hline
\end{tabular}

${ }^{*}$ significant difference. 


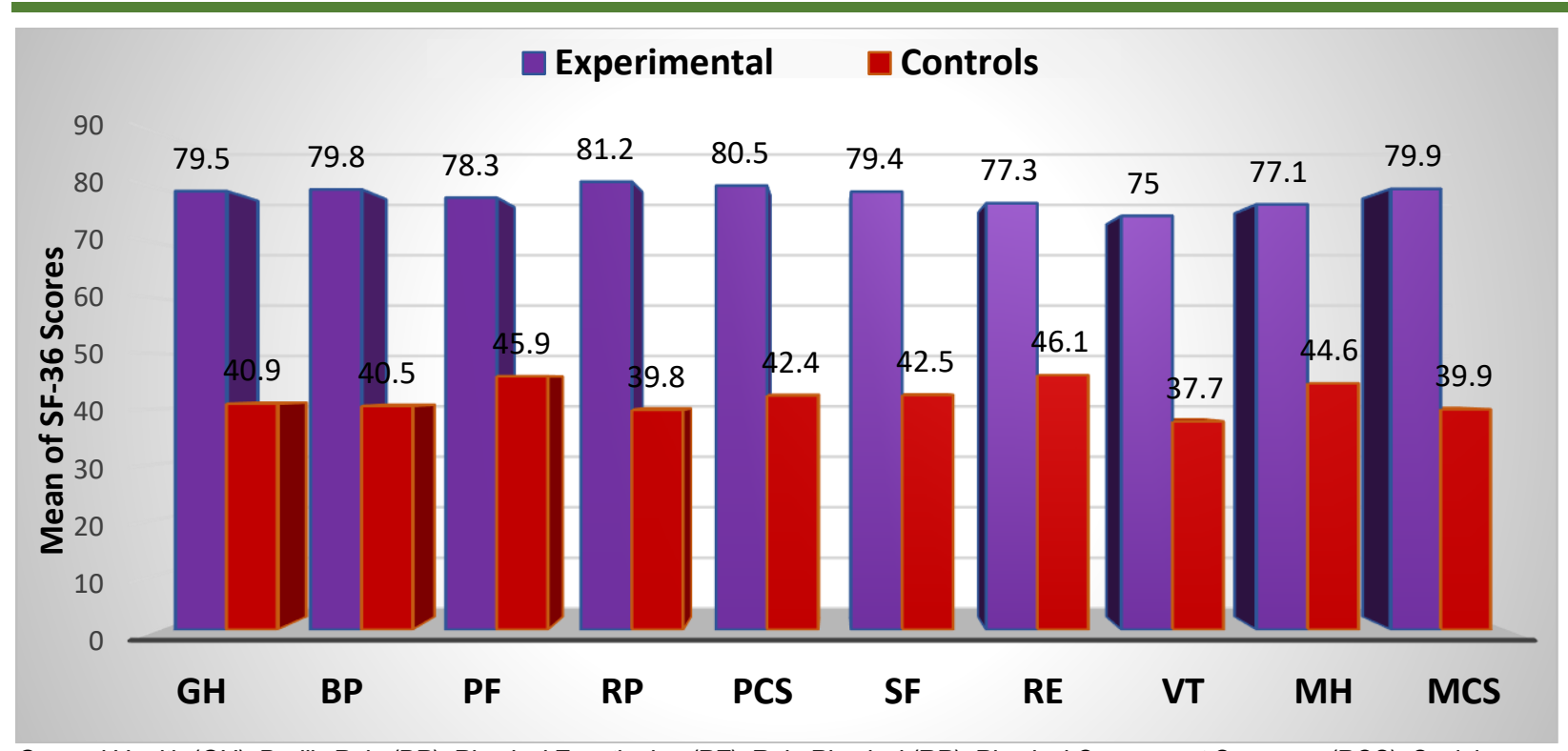

General Health (GH), Bodily Pain (BP), Physical Functioning (PF), Role Physical (RP), Physical Component Summary (PCS), Social Functioning (SF), Role Emotional (RE), Vitality (VT), Mental Health (MH) and Mental component summary (MCS).

Figure [1]: Comparison between the experimental and control groups regarding their health-related quality of life means scores after the intervention program.

\section{DISCUSSION}

In the present study we identified the prevalence rate of hypertension among adult inhabitants of Badaway village, Al-Mansoura District, Al-Dakahlia Governorate in addition. In addition, assessed the impact of health education program on HRQOL of hypertension patients?

Regarding hypertension prevalence, results of the present work was agreement with Babaee et al. ${ }^{[14]}$ study conducted among rural population in Egypt reported that $27.9 \%$ of the studied sample were hypertensive. High prevalence of hypertension in this study is probably attributable to lifestyle changes in rural areas over recent years, industrialization, urbanization, increasing economic development, modernization, market globalization. This has induced adverse diet and lifestyle changes. Which, in effect, also led to higher risk factors for hypertension such as overweight or obese [15]. This study result corresponds also with a Korean study that showed that hypertension was more prevalent among women than among men [16].

In disagreement with our study Ibrahim and Damasceno[17] conducts study in Egypt and concluded that hypertension was more prominent in men than in women. Also, in contrast to our study the prevalence among Iranians was $25.9 \%$ for men and $20 \%$ for women ${ }^{[18]}$. Such disagreement may be due to the study's self-report questionnaire design and the fact that women are generally more likely to say they are unwell than men. In addition, results of the present work coincide with Yu et al.[19] crosssectional study of 6660 people undergoing a health check in China from July to November 2012, logistic regression analyses found that advanced age and high BMI were significant risk factors for hypertension and had a positive association impact of the prevalence of hypertension in adults. This finding also agrees with the study by ElShazly and Hegazy[20] finding that age, sex, family size, socioeconomic score and occupation were the main determinants of hypertension. These results could be explained by the large over-nutrition and sedentary lifestyle in most populations associated with the occurrence of chronic diseases as hypertension[21]. A variety of factors closely related to the degree of obesity and overweight (e.g. high sympathetic tones; sodium retention; hormonal levels such as angiotensin, angiotensin II, aldosterone and leptin; and insulin resistance) may also affect blood pressure[22].

Regarding health-related quality of life among hypertensive patients compared to non- 
hypertension individuals, in agreement with our study Mohamed et al.[23] studied 600 individuals in rural areas in Egypt and found that the mean $\mathrm{HRQOL}$ scores among the hypertension community were highly significantly lower than the nonhypertensive group $(P<0.0005)$. Also, this finding agrees a study in 2002 by Al-Ghamdi et al.[24] at primary health care facilities in Al-Khobar, Saudi Arabia, for comparison the HRQOL of hypertensive patients with a control group, 404 subjects were interviewed (202 cases and 202 controls). Of age and sex, the cases and controls matched. HRQOL self-assessment patients were assessed using an Arabic version ofSF-36, a 36-item Short-Form Health Survey Questionnaire, the study concluded that the HRQOL of hypertensive patients was significantly impaired compared to the control group. For cases and controls, respectively, the mean scores for the physical component summary scale (PCS) were 39.3 and 50.8 . The mean scores for the summary scale of the mental component (MCS) were 43.7 and 50.8 respectively for cases and controls. In addition, this study coincides with the survey by Poljičanin et al.[25] that was part of the Croatian Adult Health Survey (CAHS), a crosssectional field survey that included 9,070 respondents aged 18 and over and conducted in 2003 by qualified health care professionals. The data gathered in this study provided a comprehensive health assessment of Croatian residents, including their HRQOL, using an SF-36 questionnaire and found that hypertension had negative effects on HRQOL and that all dimensions of $H R Q O L$ were lower in people with hypertension compared to healthy people. These findings might be explained by, hypertension is closely related to psychological and emotional problems, particularly in extreme stresses in life. Furthermore, the impact of hypertension on quality of life and the suggestion that people with hypertension tend to have a better mechanism to cope with and adapt to this disease ${ }^{[26]}$.

Regarding effect of an educational health program on health-related quality of life among hypertension patients: results of the present work showed agreement with the experimental study carried out by Miao et al. [27] in rural China, enrolled 1426 patients $(n=1006$ intervention group and $n=$ 420 control group) showed that the intervention in health education resulted in a significant improvement in the overall score of HRQOL SF-36 among intervention group. This result also coincides with a single-blind, randomized controlled clinical trial in Egypt by Amany et al. [28] in which 112 non-complicated, apparently healthy critical hypertensive patients with no comorbidities between 45 and 65 years of age were randomly assigned to two groups (intervention and control 1:1) at the University of Zagazig Internal Medicine. The research aimed to examine the impact of the patient-centered approach on self-reported healthrelated quality of life (HRQOL) in patients with critical hypertension attending outpatient clinic in internal medicine. This study found that patients with essential hypertension indicated worsening of HRQOL in both groups, but at the start of the study there was no statistically significant difference in HRQOL between the two groups. At the end of the study, there was a statistically significant difference between the two sample groups in terms of blood pressure control and self-reported health-related quality of life where patients in the intervention group reported statistically significant improvements in both variables.

Limiting steps of the present work includes that, the results of this study could not be generalized to rural Egypt as the data was collected from only one village. The social relationship of the researcher with the studied participants in the village facilitated the work. Also, the nature of the cross-sectional study has its limitations on causal inference between category income, occupation and the prevalence of hypertension. So, further cohort studies with follow-up data are necessary to strengthen the evidence. For example, individuals might be hypertensive before they were employed or started earning higher wages, we are not sure which came first. Finally, the data from this study is also highly dependent on the participant's answers. Memory, truthfulness, and their perception of their level of undertaking in certain questions (e.g., Income, salt usage on food, diet, minutes/hours of physical activity), can cause large errors in the results

\section{Financial and Conflict of interest disclosure}

Authors declare that there was no conflict of interest. 


\section{REFERENCES}

1. Mendis S, Davis S, Norrving B. Organizational update: the world health organization global status report on noncommunicable diseases 2014; one more landmark step in the combat against stroke and vascular disease. Stroke 2015;46(5): e121e2. DOI: 10.1161/STROKEAHA.115.008097.

2. Rizk HI, Kamal Elden NM. Body composition of women 20-49 years old as a predictor for noncommunicable diseases: a community-based study. J Egypt Public Health Assoc. 2016; 91 (1):17. DOI: 10.1097/01. EPX.0000480718. 98448.2f.

3. Ibrahim MM. Problem of hypertension in Egypt. The Egy Heart J. 2013; 65 (3):233-234. DOI: 10.1016/ j.ehj. 2013.03.005.

4. Tchicaya A, Lorentz N, Demarest S, Beissel J, Wagner DR. Relationship between self-reported weight change, educational status, and healthrelated quality of life in patients with diabetes in Luxembourg. Health Qual Life Outcomes. 2015; 13,149. DOI:10.1186/s12955-015-0348-8.

5. Baladón L, Rubio-Valera M, Serrano-Blanco A, Diego J, Fernández P. Gender differences in the impact of mental disorders and chronic physical conditions on health-related quality of life among non-demented primary care elderly patients. Qual Life Res. 2016; 25: 1461. DOI:10.1007/s11136015-1182-5.

6. Buder I, Zick C, Waitzman N. The Contribution of Physical Activity to Health-Related Quality of Life: New Population Estimates from National Survey Data. Appl Res Qual Life 2020; 15: 55-71. Doi:10.1007/s11482-018-9665-5.

7. Khaw WF, Hassan STS, Latiff AL. Comorbid conditions and health-related quality of life among hypertensive patients. Healthmed 2011; 5(1):180186. DOI: 10.3923/jms.2011.84.89.

8. Chen Q, Li S, Wang M, Liu L, Chen G. HealthRelated Quality of Life among Women Breast Cancer Patients in Eastern China. BioMed Res Int. 2018, Article ID 1452635, 12 pages. DOI: 10.1155/2018/1452635.

9. de Carvalho MV, Siqueira LB, Sousa AL, Jardim PC. The influence of hypertension on quality of life. Arq Bras Cardiol. 2013;100(2):164-174. DOI: 10.5935/abc.20130030

10. Santosa L, Chaves C, Andradeb A, Duarteb J. The influence of stress on the quality of life of hypertensive patients. Procedia - Social and Behavioral Sciences 2014; 113: 16 - 25 DOI: 10.1016/j.sbspro.2014.01.006.

11. Lee WJ, Song KH, Noh JH, Choi YJ, Jo MW. Health-related quality of life using the EuroQol 5D questionnaire in Korean patients with type 2 diabetes. J Korean Med Sci. 2012;27(3):255-60. DOI: 10.3346/jkms.2012.27.3.255.

12. Saleem F, Hassali MA, Shafie AA, UI Haq N, Farooqui M, Aljadhay H, Ahmad FU. Pharmacist intervention in improving hypertension-related knowledge, treatment medication adherence and health-related quality of life: a non-clinical randomized controlled trial. Health Expect. 2015; 18 (5):1270-81. DOI: 10.1111/hex.12101.

13. Xiao M, Zhang F, Xiao N, Bu X, Tang X, Long Q. Health-related quality of life of hypertension patients: a population-based cross-sectional study in Chongqing, China. Int J Environ Res Public Health. 2019 ;16(13):2348. DOl: 10.3390/ ijerph 16132348.

14. Babaee Beigi MA, Zibaeenezhad MJ, Aghasadeghi K, Jokar A, Shekarforoush S, Khazraei $\mathbf{H}$. The effect of educational programs on hypertension management. Int Cardiovasc Res J. 2014;8(3):94-8. PMID: 25177671

15. Mashahit M, Hoda Hussein H, Hanafy E. Screening for non-communicable diseases in public places in upper Egypt. Asian J Med Health. 2017:1-6. DOI: DOI: 10.9734/AJMAH/ 2017/ 36090.

16. Choi HM, Kim HC, Kang DR. Sex differences in hypertension prevalence and control: Analysis of the 2010-2014 Korea National Health and Nutrition Examination Survey. PLoS One 2017; 12.5: e0178334. DOI: 10.1371/journal. Pone. 0178334.

17. Ibrahim MM, Damasceno A. Hypertension in developing countries. Lancet 2012; 380 (9841): 611-619. DOI:10.1016/s0140-6736(12)60861-7.

18. Soubeiga JK, Millogo T, Bicaba BW, Doulougou B, Kouanda S. Prevalence and factors associated with hypertension in Burkina Faso: a countrywide cross-sectional study. BMC Public Health 2017; 17-64. DOI:10.1186/s12889016-3926-8.

19. Yu J, Zou DS, Xie MT, Ye Y, Zheng TP, Zhou SX, et al. The interaction effects of risk factors for 
hypertension in adults: a cross-sectional survey in Guilin, China. BMC Cardiovasc Disord. 2016; 16 (1):183. DOI:10.1186/s12872-016-0358-4.

20. EIShazly HM, Hegazy NN. Socioeconomic determinants affecting the quality of life among diabetic and hypertensive patients in a rural area, Egypt. J Family Med Prim Care. 2017;6(1):141145. DOI: 10.4103/ffmpc.jfmpc_31_17.

21. da Silva AA, do Carmo J, Dubinion J, Hall JE. The role of the sympathetic nervous system in obesity-related hypertension. Current Science Inc. 2009; 11, 206. DOl:10.1007/s11906-009-0036-3.

22. Kotsis V, Stabouli S, Papakatsika S, Rizos Z, Parati G. Mechanisms of obesity-induced hypertension. Hypertens Res. 2010; 33: 386-393. DOl:10.1038/hr.2010.9.

23. Gabal MS, Abd Elaziz KM, Mostafa NS, Khallaf MK. Prevalence of Hypertension and Quality of Life among Hypertensive Patients in An Egyptian Village. Egy J Community Med 2018; 36(2): 23-35. DOI: 10.21608/ejcm.2018.11046.

24. Al-Ghamdi MS, Taha AZ, Ahmad B, Khalil MS. Quality of life in a sample of hypertensive patients attending primary health care facilities in AlKhobar, Saudi Arabia. J Family Community Med. 2002;9(1):25-32. PMID: 23008659.
25. Poljičanin T, Ajduković D, Šekerija M, Željko Metelko Z, Vuletić Mavrinac G. Diabetes mellitus and hypertension have comparable adverse effects on health-related quality of life. BMC Public Health 2010;10(1):12. DOI:10.1186/1471-245810-12.

26. Everson SA, George AK, Debbie EG, Jukka TS. Hypertension incidence is predicted by high levels of hopelessness in Finnish men. 2000;35(2):5617. DOI:10.1161/01.HYP.35.2.561.

27. Miao Y, Zhang L, Sparring V. Improving health related quality of life among rural hypertensive patients through the integrative strategy of health services delivery: a quasi-experimental trial from Chongqing, China. Int J Equity Health. 2016; 15 , 132. DOl:10.1186/s12939-016-0421-x.

28. Abd Allah AM, Ahmed MM, Foda MS, Saad NE. Patient Centered Approach and Health Related Quality of Life in Essential Hypertensive Patients, Eur J Preven Med. 2016; 4 (4): 100-105. DOI: 10.11648/j.ejpm.20160404.12. 